Supplementary Information for

\title{
Molecular orientation and strain-induced crystallization in
}

\section{trans-polypentenamer}

Carlos R. López-Barrón, Brian Rohde, Alexander V. Zabula,

Jonathan J. Schaefer and Joseph A. Throckmorton

ExxonMobil Chemical Company, Baytown, Texas 77520, USA

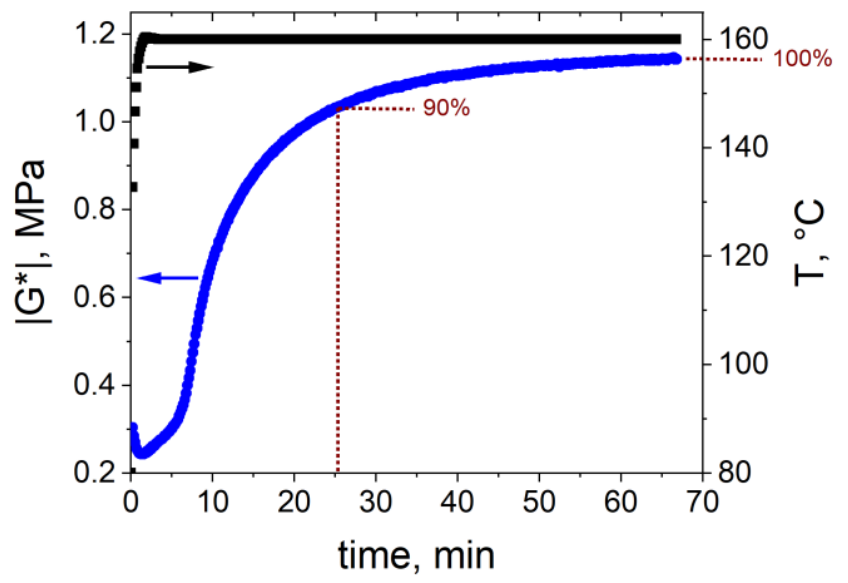

Figure S1. Vulcanization (cure kinetics) curve for the CPR sample measured at $160{ }^{\circ} \mathrm{C}$. Dotted lines indicates $100 \%$ and $90 \%$ cure state. 


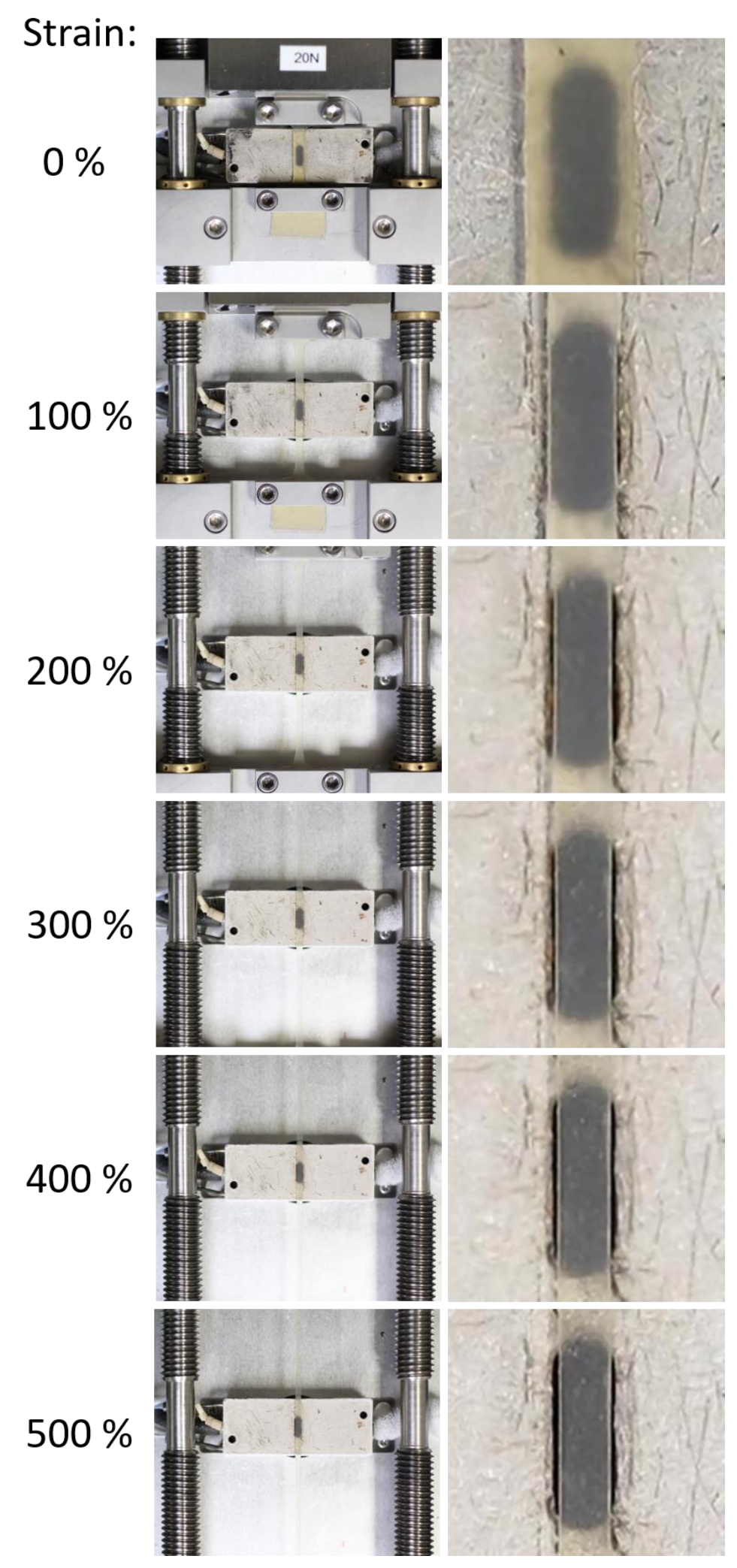

Figure S2. Photographs of a CPR specimen being stretched in the Linkam ${ }^{\mathrm{TM}}$ tensile stage at $0{ }^{\circ} \mathrm{C}$. 


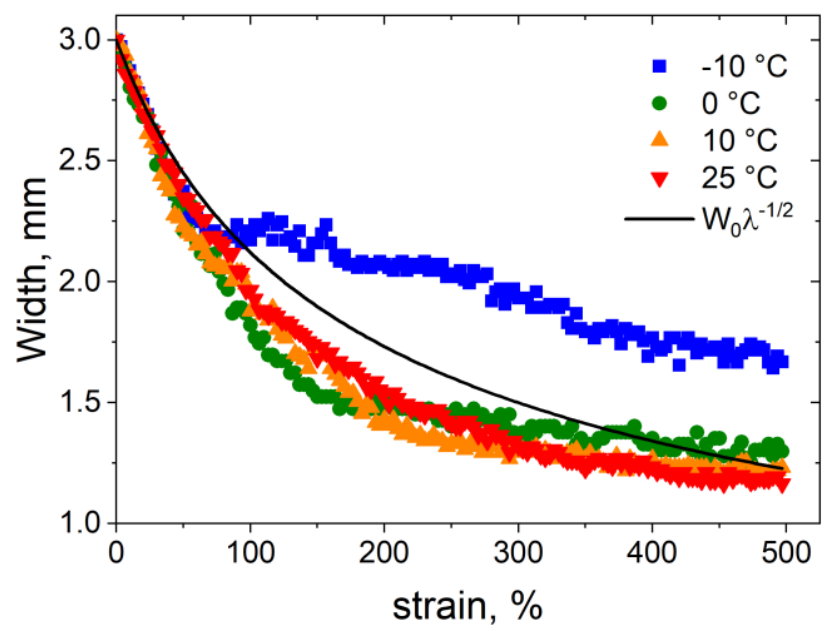

Figure S3. Width of the CPR specimen as a function of (engineering) strain measured at the center of the specimen at the indicated temperatures.

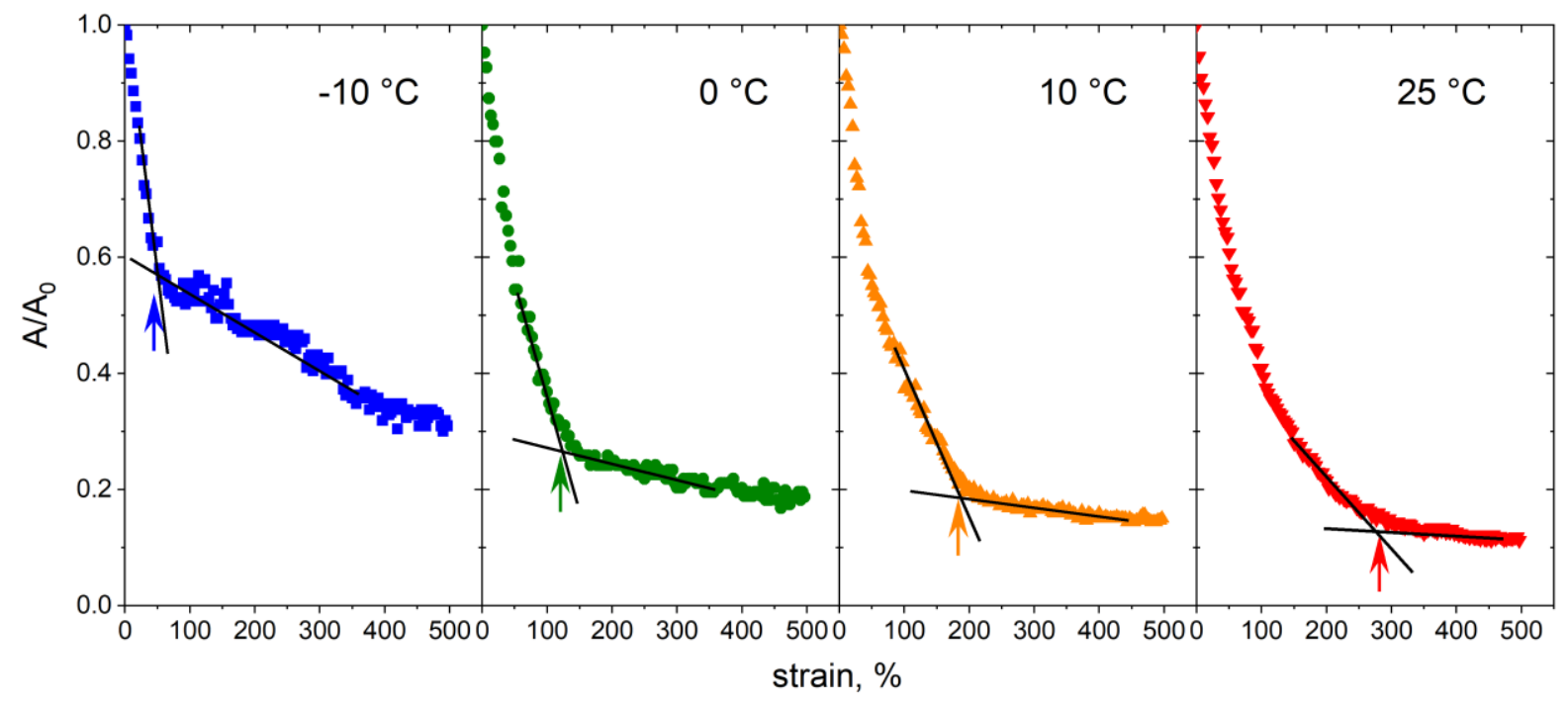

Figure S4. Normalized cross section area versus (engineering) strain for the CPR specimens measured at the indicated temperatures. The arrows indicate the onset of SIC. 


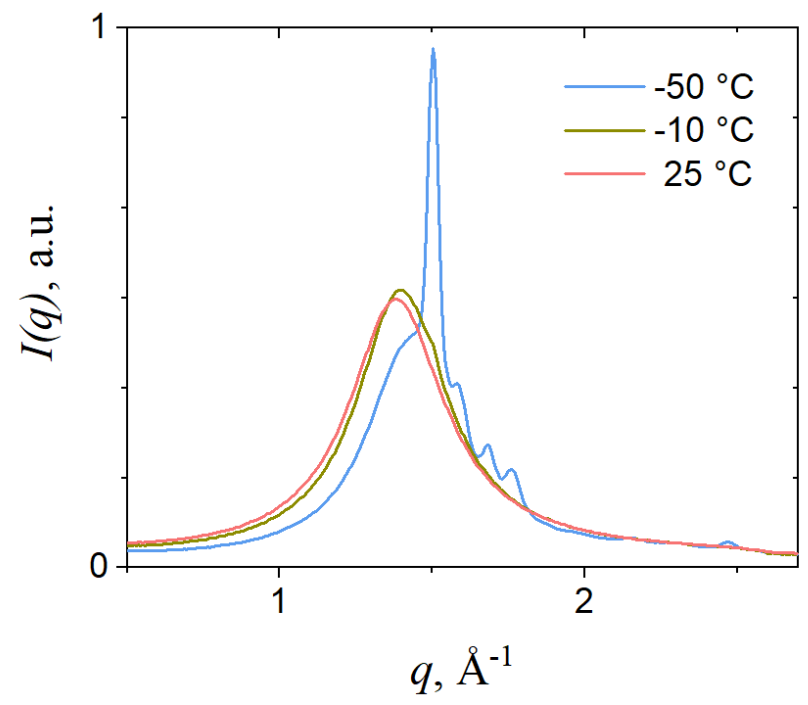

Figure S5. Azimuthally-averaged WAXS profiles measured quiescently (without any deformation) as at the indicated temperatures.

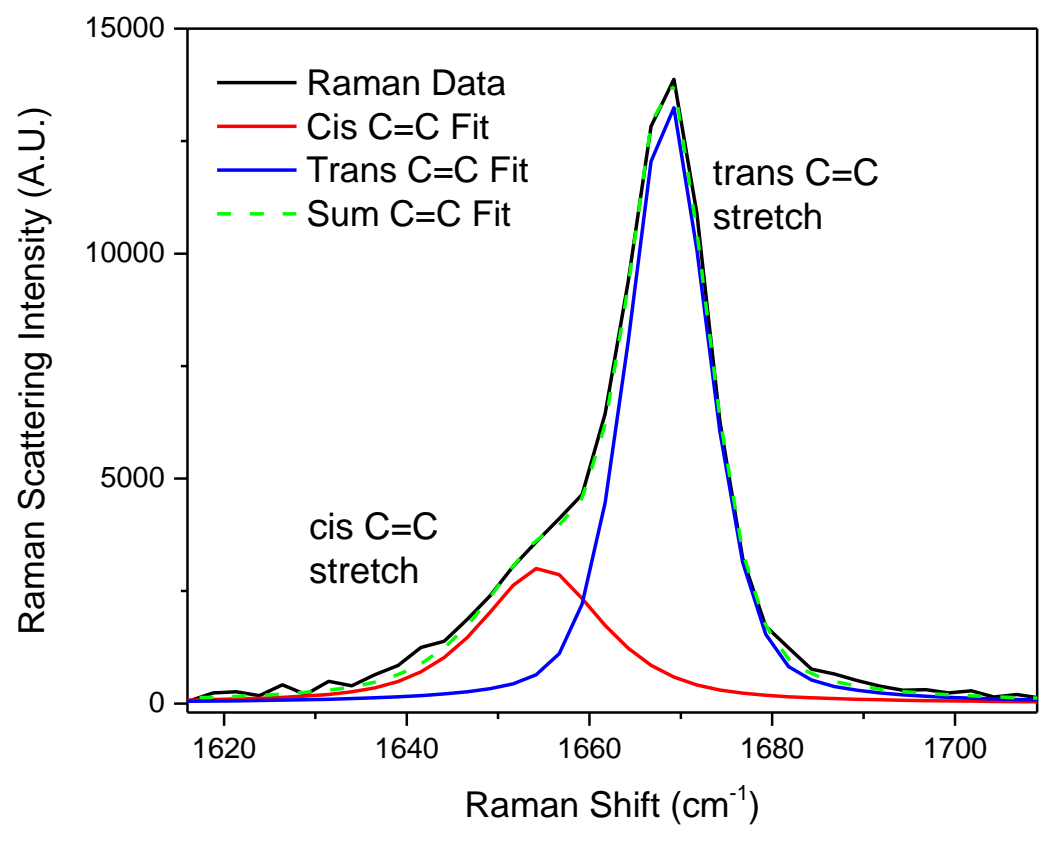

Figure S6. Raman spectrum of $\mathrm{C}=\mathrm{C}$ stretch region with individual Gaussian fitting of the cis and trans conformers at 1654 and $1668 \mathrm{~cm}^{-1}$ respectively. Dashed line represents the sum of the two Gaussian fit lines. 


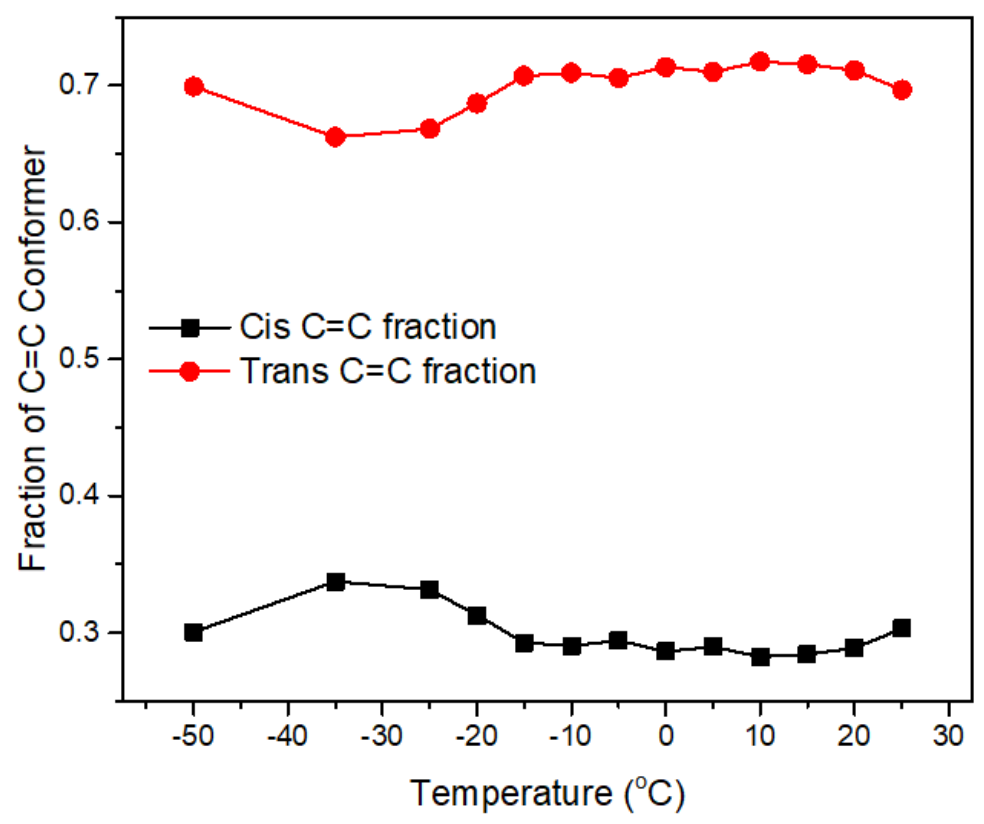

Figure S7. CPR polymer cisltrans $\mathrm{C}=\mathrm{C}$ conformer fraction over the temperature range of -50 to 25 ${ }^{\circ} \mathrm{C}$ determined from Raman spectra.
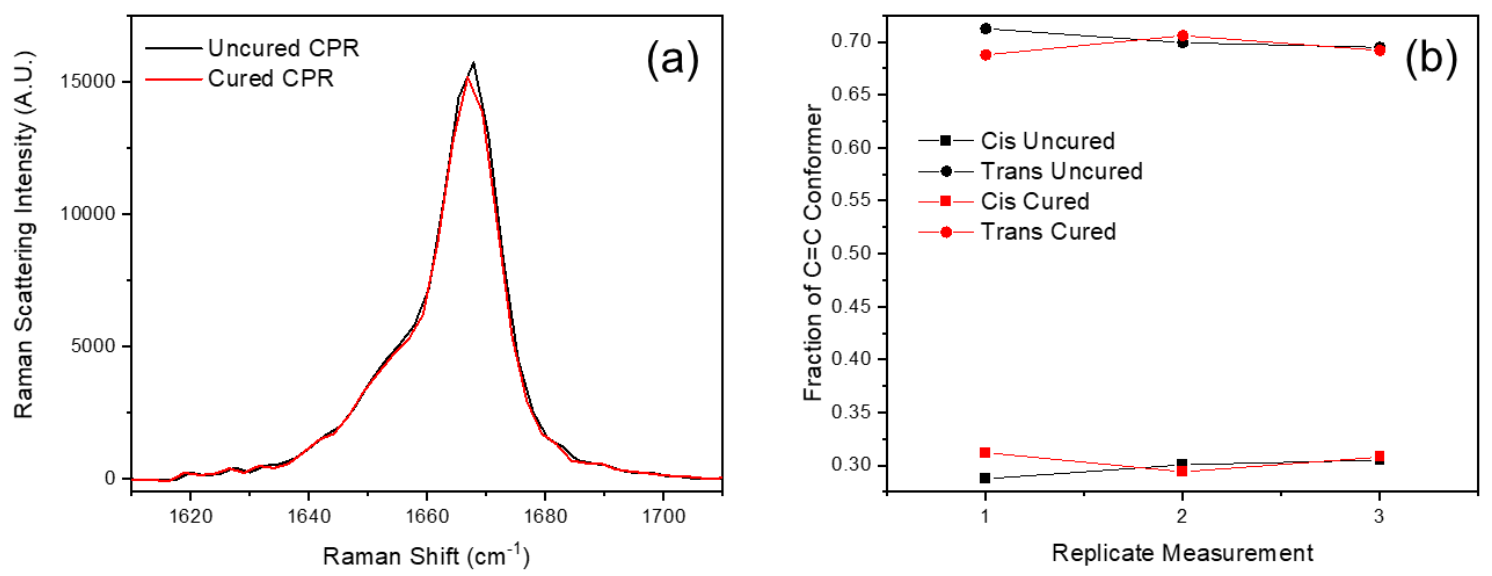

Figure S8. (a) Raman spectra of the $\mathrm{CPR}$ rubber $\mathrm{C}=\mathrm{C}$ double bond region before and after curing, demonstrating no significant change in the cisttrans $\mathrm{C}=\mathrm{C}$ double bond content. (b) Triplicate measurements of the relative amounts of cisltrans $\mathrm{C}=\mathrm{C}$ double bond content from fitting Gaussian peaks of uncured and cured CPR. 


\section{Isothermal crystallization of CPR}

DSC isothermal measurements were performed using a DSC2500 ${ }^{\mathrm{TM}}$ (TA Instruments). The thermal history of the vulcanized CPR sample was erased by holding for 5 minutes at $80^{\circ} \mathrm{C}$. Then, a fast cooling (at $100^{\circ} \mathrm{C} / \mathrm{min}$ ) down to a constant "isothermal" temperature, $T_{i s o}$, was performed. $T_{i s o}$ ranged from $-20{ }^{\circ} \mathrm{C}$ to $0{ }^{\circ} \mathrm{C}$. At that temperature, the sample was held for $120 \mathrm{~min}$, and the heat flow was recoded as a function of time. Figure S9(a) shows the isothermal DSC traces of the CPR sample at different temperatures. Note that these data correspond to the heat flow measured at $T_{\text {iso, }}$, minus background data which consist of heat flow measured at $T_{m}$. This subtraction ensures that the data shown in Figure S9(a) corresponds to the heat flow due solely to crystallization, as no crystallization can occur at $T_{m}$. The inset in Figure S9(a) shows a closeup of the measurements performed at $T_{i s o}=-10{ }^{\circ} \mathrm{C}$ and $0{ }^{\circ} \mathrm{C}$. A clear crystallization peak is observed at $-10{ }^{\circ} \mathrm{C}$, whereas no heat flow due to crystallization can be detected at $0{ }^{\circ} \mathrm{C}$.
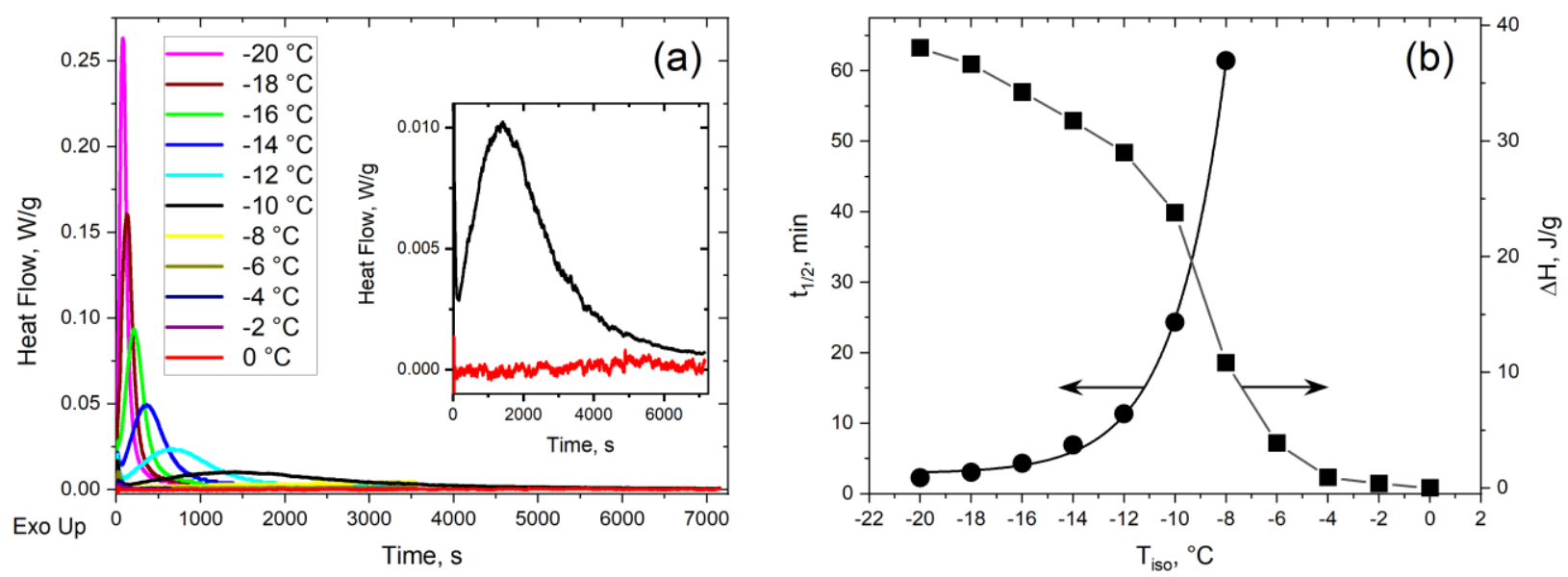

Figure S9. Isothermal DSC measurements. (a) DSC scans at the different $T_{\text {iso }}$, as indicated. Inset: detail of the scans at $-10^{\circ} \mathrm{C}$ and $0{ }^{\circ} \mathrm{C}$. (b) half crystallization time and enthalpy of crystallization, as a function of $T_{i s o}$.

Half crystallization time $\left(t_{1 / 2}\right)$ was characterized as the peak position in the crystallization peaks shown in Figure S9(a), and plotted as a function of $T_{i s o}$ in Figure $\mathrm{S} 9(\mathrm{~b})$. The enthalpy of crystallization $(\Delta H)$, computed by integration of the heat flow data in Figure S9(a), is also shown as a function of $T_{i s o}$ in Figure S9(b). Note that this enthalpy corresponds to $120 \mathrm{~min}$ of heat flow, which does not cover the whole isothermal crystallization peak for $T_{i s o}>-10{ }^{\circ} \mathrm{C}$. $t_{1 / 2}$ is an exponential function of $T_{i s o}$, which diverges to very long values $(>120 \mathrm{~min})$ at $T_{\text {iso }}>-8{ }^{\circ} \mathrm{C}$. This divergence coincides to the transition to very low enthalpy values in the sigmoidal function 
describing $\Delta H\left(T_{\text {iso }}\right)$. At $T_{i s o}=-10{ }^{\circ} \mathrm{C}, t_{1 / 2}=24.5 \mathrm{~min}$ and the crystallization onset occurs at $\mathrm{t} \sim 3$ min, which explains the quiescent crystallization observed during loading of the dogbone specimens at this temperature (see Figures 3 and 4 ). At $0{ }^{\circ} \mathrm{C}$, the crystallization is completely hampered, as evidenced by the values of $t_{1 / 2} \gg 120 \mathrm{~min}$ and $\Delta H=0 \mathrm{~J} / \mathrm{mol}$. 